\title{
Influence of composite particle formation on the performance and economics of grit removal
}

Judd, S.J. ${ }^{1,4}$, Khraisheh, M. ${ }^{2}$, Al-Jami, K.L. ${ }^{2}$, M., Jarman, D. ${ }^{3}$, and Jahfer, T. ${ }^{4}$

${ }^{1}$ Gas Processing Center, Qatar University, Qatar

${ }^{2}$ Department of Chemical Engineering, Qatar University, Qatar

${ }^{3}$ Hydro International Ltd., UK

${ }^{4}$ Cranfield University, Cranfield, UK

\section{ABSTRACT}

Grit is routinely removed at the headworks of municipal wastewater treatment works to limit its onerous impact on downstream processes. Grit separation technologies are normally based on sedimentation of an homogeneous material (usually sand). However, in practice inorganic grit particles are likely to be combined with organic matter, such as fats oils and grease (FOG), producing a composite particle whose settling properties vary with the inorganic/organic content.

A study of the impact of particle composition on its sedimentation has been conducted encompassing theoretical description (for particle settling in transitional flow), practical measurement and economic analysis. Practical measurement included sedimentation tests of homogeneous and composite particles along with characterisation of accumulated granular material sampled from actual municipal wastewater treatment works. The economic assessment was based on data from full-scale installations in the UK and US pertaining to remedial measures undertaken as a result of grit impacts, primarily accumulation in vessels and channels and damage of mechanical equipment through abrasion.

Practical tests revealed coating of the sand grains with a FOG analogue (candlewax) to generate composite particles containing $45 \%$ wax by weight. The coated particles were then $30 \%$ less dense, $22 \%$ larger and $14 \%$ less settleable, on average, than the uncoated particles. Samples of accumulated grit taken from anaerobic digesters and aeration lanes from a full-scale plant indicated a FOG content (43\%) similar to that of the waxed particles in the bench-scale tests, thus leading to a similar grain retardation of $14 \%$ assuming the FOG to be entirely associated with the grit. An assessment of the impact of the consequential breakthrough of grit particles due to buoyancy generated by composite particle formation indicated a $\$ 1.1$ increase in operating costs per megalitre (ML) wastewater.

Keywords: Grit removal; organic matter; composite particle; settling velocity; transitional flow; cost. 


\section{Introduction}

Particle sedimentation in water forms a key part of subject areas such as powder technology (Shahi and Kuru, 2015; Terfous et al, 2013) and river bed sediment hydraulic characterisation (Maggi, 2013; Cuthbertson and Ervine, 2007). The modelling of particle settlement generally, and in turbulent flow (Mazzuoli et al, 2014; McNair and Newbold, 2012) specifically, remains a challenge for researchers in this area. Analytical expressions defining particle settlement, primarily through the drag coefficient, have been presented in research literature dating back several decades, with recent papers summarising the various equations developed (Betancourt et al, 2015; Yang et al, 2015; Terfous et al, 2013). Indeed, a series of papers authored by Concha and co-workers providing theoretical particle settlement expressions covering a wide range of conditions have been published since 1979 (Betancourt et al, 2015; Concha and Almendra, 1979). The majority of the modelling approaches are ultimately designed to reconcile the dependence of the drag coefficient on both the flow regime (within the transitional region) and the particle characteristics, in generating analytical expressions.

Whilst numerous theoretical and semi-empirical expressions of particle settlement have been presented the practical implications of these with reference to grit removal systems specifically appears to have been largely overlooked. A review of the SCOPUS database reveals that there are approximately 60 papers dedicated to the removal of grit from wastewaters, with less than $40 \%$ of these appearing in index-linked journals. Around $25 \%$ of the total number concern hydrodynamic modelling (Dutta et al, 2014; Munoz and Young, 2009), and a further 60-65\% are based grit characterisation (Sherony and Herrick, 2015; Hafiz, 2013; Osei et al, 2012) and degritter performance evaluation (Yan et al, 2014; McNamara et al, 2012), a significant proportion of the latter being site specific. Notwithstanding the apparent paucity of research into degritting technology per se, the vast majority of large municipal wastewater treatment works (WwTWs) are fitted with degitters whose operation is based on sedimentation of entrained heavy suspended solids.

Grit in wastewater takes the form of inorganic solid particles in the $0.2-4 \mathrm{~mm}$ size range of density predominantly above $1800 \mathrm{~kg} / \mathrm{m}^{3}$ (Table 1 ). Whilst organic matter is retained in the grit waste, degritters are intended to selectively remove solids, which may otherwise impair downstream processes through abrasion (of mechanical equipment or concrete channels) or accumulation, most typically in anaerobic digesters (ADs) or aeration lanes. This stipulates the larger inorganic solids, and the standard performance criteria used for the degritter technology is $95 \%$ removal of such solids above $210 \mu \mathrm{m}$ in size, based on national standards (USEPA, 2003).

However:

a) Recent reported practitioner accounts and experiences (Sherony and Herrick, 2015; Flanagan, 2014; McNamara et al, 2013, 2012) suggest that grit entrainment imposes a challenge even for degritters apparently meeting the specification, with significant adverse consequences for downstream unit process and equipment, and

b) The combination of grit with organic matter, and specifically fats, oils and grease (FOG), whilst being noted in WwTW grit samples (Flanagan, 2014) has never been quantified with respect to its extent and calculable impact on grit removal efficacy. 
The study aims to investigate both the impact of coating of grit particles on sedimentation and the cost associated with residual grit on downstream wastewater unit processes. The work described provides:

1. experimental determination of the impact of FOG coating of granular solids to form composite particles on their settling velocity;

2. comparison of the recorded trends with those of model composite spherical particles;

3. determination of the composition of grit accumulated within components of full-scale municipal WwTWs; and

4. the use of real-life economic data to determine the cost of retarded settling.

Table 1: Grit size range, specific gravity, shape, source, estimated settling velocity.

\begin{tabular}{|c|c|c|c|c|c|}
\hline Grit component & $d_{p}, \mu m$ & $\begin{array}{l}\text { Specific } \\
\text { gravity (-) }\end{array}$ & Source & Shape & $v_{s}, \mathrm{~mm} / \mathrm{s}$ \\
\hline Quartz Sand $^{1,3,7,8}$ & $212-300$ & 1.2 & Infiltration & Granular & $28-40$ \\
\hline Limestone in grit ${ }^{1,3,7}$ & $500-1000$ & 2.85 & Infiltration & variable & $30-60$ \\
\hline Granite (fracture) ${ }^{1,7,8}$ & $1000-2000$ & 2.66 & erosion & Angular & $50-100$ \\
\hline Gravel (Granule gravel) $2,4,6,7$ & $2000-4000$ & 2.0 & erosion & variable & $50-100$ \\
\hline Clay $1,3,4,7$ & $<5.0$ & 1.8 & Infiltration & sphere & $<4.5$ \\
\hline Sand, wet ${ }^{1,3,5}$ & $190-275$ & 1.92 & Infiltration & variable & $24-39$ \\
\hline Silt $1,3,5$ & $5.0-80$ & $2.5-2.6$ & Municipal waste & variable & 4.7 \\
\hline Organic waste ${ }^{1,3,8}$ & $300-6720$ & 0.72 & Municipal waste & variable & $9-12$ \\
\hline Inorganic food waste $4,7,8$ & $100-840$ & $1.07-2.2$ & Municipal waste & variable & $1-10$ \\
\hline $\begin{array}{l}\text { Undigested organics (bones, teeth, } \\
\text { etc.) }\end{array}$ & $3.0-1000$ & $0.8-0.9$ & Mixed waste & variable & $1-10$ \\
\hline Fats, oils \& grease ${ }^{4,6,7}$ & Various & $0.5-0.7$ & Mixed waste & Mild & \\
\hline Mixed grit ${ }^{1,3}$ & $>210$ & 2.65 & Mixed waste & variable & $1.4-14$ \\
\hline
\end{tabular}

${ }^{1}$ Aidun, 2013; ${ }^{2}$ Csgnetwork, 2016; ${ }^{3}$ Flanagan, 2014; ${ }^{4}$ Maggi, 2013; ${ }^{5}$ Sherony, 2014; ${ }^{6}$ Simetric, 2016; ${ }^{7}$ Sperling, 2007; ${ }^{8}$ Yesiller et al., 2014

\section{$2 \quad$ Materials and Methods}

\section{$2.1 \quad$ Grit samples and physical models}

Real and model homogeneous and composite grit samples took the form of:

a) microsphere standards (Table 2), supplied by Cospheric, CA, USA,

b) fractionated sand grains of mean material density $2650 \mathrm{~kg} / \mathrm{m}^{3}$,

c) coated fractionated sand, using candlewax as a FOG analogue, and

d) whole samples of accumulated solids extracted from unit processes (ADs and aeration lanes) from four different UK sites (Table 3).

The microspheres were of three different materials and particle sizes, with the material density generally decreasing with increasing size (Table 2) to mimic the effect of the coating of grit particles with FOG. The sand grains were fractionated using graded sieves according to standard particle fractionation methods (British Standard, 1990). A proportion of the 1-1.2 mm size range of fractionated material was then coated with molten candlewax $\left(910 \mathrm{~kg} / \mathrm{m}^{3}\right.$ solid density) to represent FOG-coated particles. 40-100 of the coated particles were then optically analysed and the cross-sectional area $A$ determined using ImageJ digital image analysis software (Cherian et al, 2014), the grain size then taken as $2(A / \pi)^{0.5}$. A sufficiently large number of the particles (100250) were also weighed to produce sufficient mass for accurate determination on a four-figure 
WR36544: Composite particle formation impacts on grit removal

balance, so as to allow the density of the material to be measured from the mass and volume of the sphere.

Table 2: Model and sand particles

\begin{tabular}{l|lll}
\hline Material & Code & $\begin{array}{l}\text { Specific gravity } \\
\text { ) }\end{array}$ & Dia, (mm) \\
\hline Microspheres & & 1.09 & \\
Polyethylene & $P E$ & 1.3 & 0.55 \\
Cellulose acetate & $C A, 1$ & 1.3 & 1 \\
Cellulose acetate & CA, 1.2 & 2.54 & 0.2 \\
Soda lime glass & SLG,0.65 & 2.54 & 0.69 \\
Soda lime glass & SLG,0.69 & 4.15 & 0.27 \\
Barium titanate & BaT,0.27 & 4.15 & 0.52 \\
Barium titanate & BaT,0.52 & & \\
Sand grains & & 2.65 & 1.21 \\
Sand & Sand & 1.86 & 1.48 \\
Coated sand & Waxed sand & & \\
\hline
\end{tabular}

Table 3: Digester samples

\begin{tabular}{l|lll}
\hline Site & Degritter technology & Sample position & Date sampled \\
\hline Site A & Detritor & Middle digester & $15 / 8 / 15$ \\
Site A & Detritor & Side digester & $15 / 8 / 15$ \\
Site B & Unknown & Middle digester & $19 / 3 / 15$ \\
Site B & Unknown & Side digester & $19 / 3 / 15$ \\
Site C & Detritor + constant velocity channel & Top layer sludge & $7 / 8 / 15$ \\
Site C & Detritor + constant velocity channel & Lower layer sludge & $7 / 8 / 15$ \\
Site D & Aerated channel & $0.5 \mathrm{~mm}$ screening* & $28 / 8 / 15$ \\
Site D & Aerated channel & $5 \mathrm{~mm}$ screenings* & $28 / 8 / 15$ \\
Site D & Aerated channel & $0.5 \mathrm{~mm}$ screening* & $28 / 8 / 15$ \\
Site D & Aerated channel & 5 mm screenings* & $28 / 8 / 15$ \\
Site E & Constant velocity channel & Aeration lanes & $4 / 11 / 15$ \\
\hline
\end{tabular}

*washed through screens with water

Particle settling velocity $\left(v_{s}\right)$ for the fractionated sand and microspheres was determined by releasing the particles into a $1.5 \mathrm{~m}$ high, $100 \mathrm{~mm}$ diameter column of water. The time taken for the particles to traverse $1 \mathrm{~m}$, the particles assumed to have reached terminal velocity after $0.5 \mathrm{~m}$, was recorded for 20-50 particles, along with the water temperature. The mean and standard deviation $v_{s}$ values were then calculated for each data set.

In the case of the grit samples from the digesters and aeration lanes of UK WwTW sites particle size distribution was determined through sieve grade analysis, and sedimentation rates by the established column method (Tyack et al, 1996). The organic content of grit was determined by ashing the sample according standard methods (British Standard, 1990).

\subsection{Mathematical modelling}

Two analytical expressions for particle settling under transitional flow conditions were considered. A simple expression for settlement of large (up to $\sim 1.7 \mathrm{~mm}$ diameter) dense particles is (Crittendan et al, 2012): 
WR36544: Composite particle formation impacts on grit removal

$$
\begin{aligned}
& \text { Vs } \\
& =\left(\underline{\text { g. } d^{1.6} \cdot\left(\rho_{p}-\rho\right)}\right)^{1 / 1.4}
\end{aligned}
$$

where $\mathrm{g}$ is acceleration due to gravity, $d$ the particle diameter, $\rho_{p}$ and $\rho$ are the particle and water densities respectively and $\mu$ the viscosity. An alternative semi-empirical expression has been proposed which is specific to sand grains settling in the transitional region (Alcerreca et al, 2013):

$$
R e=\frac{\rho v_{s} d}{\mu}=\left(\sqrt{22+1.13 D_{*}^{2}}-4.67\right)^{1.5}
$$

where the non-dimensionalised grain diameter $D_{*}$ is given by:

$$
D_{*}=d^{3} \sqrt{\frac{g \rho^{2}}{\mu^{2}}\left[\frac{\rho_{p}}{\rho}-1\right]}
$$

The full non-analytical solution for $v_{s}$ for spherical particles may be determined iteratively according to Turton and Levenspiel (1986):

$$
\begin{aligned}
v_{s} & =\sqrt{\frac{4 d g\left(\rho_{p}-\rho\right)}{3 \rho C_{D}}} \\
\text { where } C_{D} & =\frac{24}{R e}\left(1+0.173 R e^{0.657}\right)+\frac{0.413}{1+16300 R e^{-1.09}}
\end{aligned}
$$

Viscosity $\mu$ can be determined from the water temperature $T$ in ${ }^{\circ} \mathrm{K}$ by the general expression (Moaveni, 2011):

$$
\mu=2.414 \times 10^{-5} 10^{247.8 /(T-140)}
$$

The overall composite particle size $d_{c}$ and density $\rho_{c}$ are obtained from a consideration of the coating of a spherical grain particle of size $d_{\text {grit }}$ and density $\rho_{\text {grit }}$ with the FOG of density $\rho_{F O G}$, viz::

$$
\begin{array}{ll}
d_{c} & =\frac{d_{\text {grit }}}{\sqrt[3]{(1-\theta)}} \\
\rho_{c} & =\theta \rho_{F O G}+(1-\theta) \rho_{\text {grit }}
\end{array}
$$

where $\theta$ is the fractional FOG content of the composite particle. Equations 7-8 assume the uncoated grain to be impervious to the FOG, such that all the FOG forms a discrete layer on the grit surface. If the densities of the grit and FOG are fixed, their relative proportions can be determined based on the mean size and mass of the composite (waxed) sand grains and the $v_{s}$ values compared with those of both the model particles (microspheres) and theoretical predictions.

\subsection{Cost analysis}

Cost information relating to grit arising in WwTW was obtained directly from water utilities and municipalities in the UK and the US through liaison with asset managers and other stakeholders within the individual organisations. 11 data in total were obtained specifically relating to grit removal and abrasion, viz:

a) Cleaning out of the anaerobic digesters (4 data)

b) Cleaning out of the aeration lanes (3 data)

c) Primary settlement tank refurbishment (1 datum) 
d) Abraision of mechanical equipment (2 data) and concrete channels (1 datum)

\section{Results and discussion}

\subsection{Particle size, composition and sedimentation determination}

\subsubsection{Coated/uncoated grit and microsphere size and settling velocity}

Measured mean $v_{s}$ values for the model microspheres were found to be in good agreement generally within 6\% - with the general expression (Equations 4-5) of Turton and Levenspiel (1986). Deviation from this expression was apparent for the uncoated and coated sand grains (Fig. 1), for which both sets of data were somewhere between the values predicted by Equations 1 and 2-3, provided by Crittendan et al (2012) and Alcerreca et al (2013) respectively. These outcomes are to be expected, given the reduced sphericity of the sand grains and the associated increased drag for which the semi-empirical expressions account.

Having appraised the applicability of the expressions, the percentage retardation of the particle on increasing the coating can be determined using Equations 7-8 to calculate the impact on the coating on the size and overall density and Equations 1-6 as before to compute settling velocity (Fig. 2). A density of $880 \mathrm{~kg} / \mathrm{m}^{3}$ was assumed for the FOG for the computed projections, a somewhat conservative estimate given that FOG density may apparently be as low as $500 \mathrm{~kg} / \mathrm{m}^{3}$ (Sherony, 2014; Sperling, 2007). Measurement of the mean size and weight per coated and uncoated sand grain revealed the coating to make up $\sim 45 \%$ of the total particle volume.

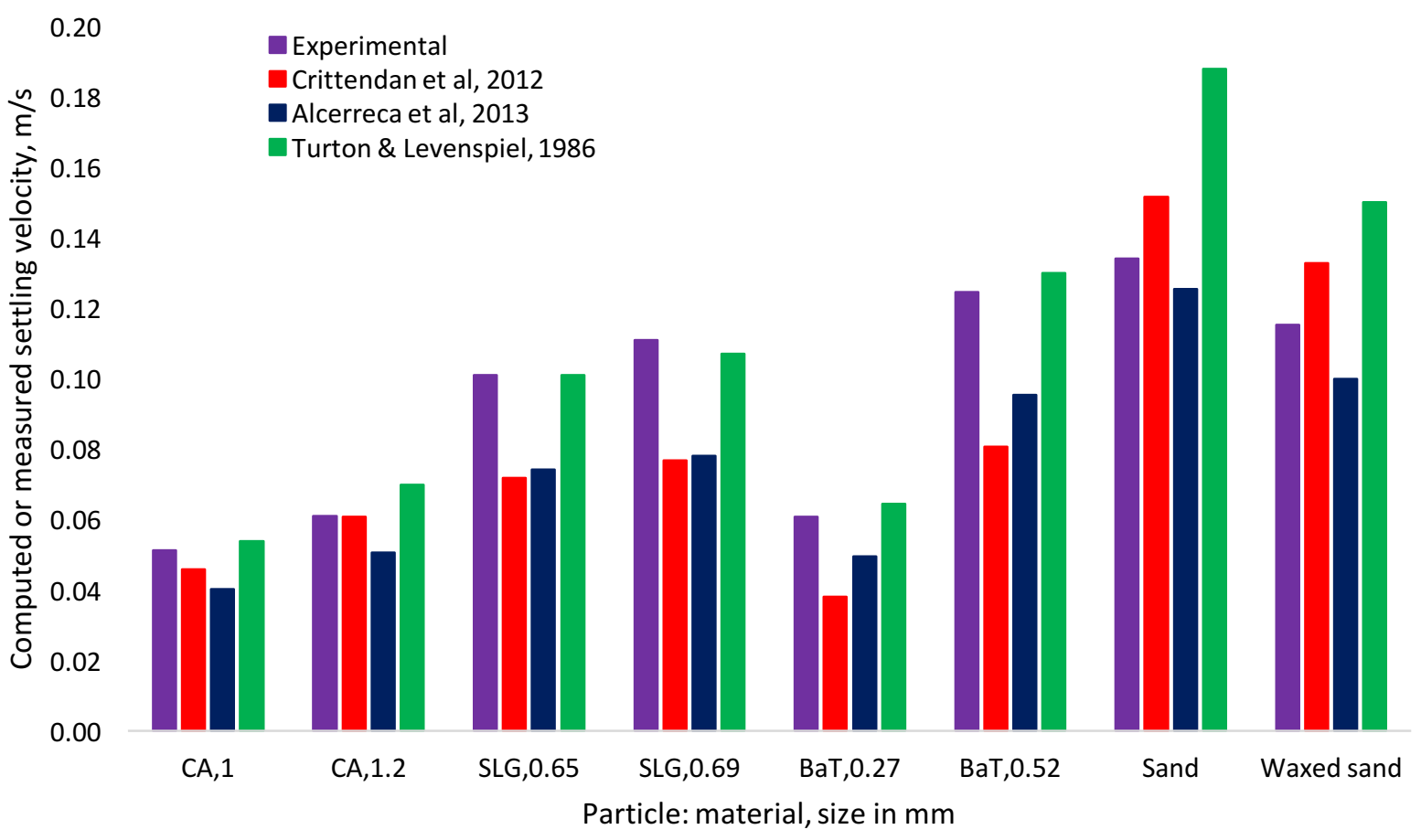


Figure 1: Experimentally-measured vs. computed theoretical settling velocities for different materials (see Table 2) and model representations. All experimental measurements subject to $7-15 \%$ standard deviation of the mean.

The experimental data was most closely aligned with the simple analytical expression of Crittendan et al, 2012 (Equation 1), although the projected settling velocities according to Alcerra et al, 2013 (Equations 2-3) are within experimental error. Clearly, further experimental data points would be needed with greater precision to confirm the veracity of the equations, demanding coating techniques more advanced than that used in the current study. However, it is apparent that a $13-14 \%$ reduction in settling velocity is produced on coating the particle with 880 $\mathrm{kg} / \mathrm{m}^{3} \mathrm{FOG}$ solids to form a particle of 45 volume \% FOG, 55\% sand. According to Equation 1, the retardation is increased to $18 \%$ for a $880 \mathrm{~kg} / \mathrm{m}^{3} \mathrm{FOG}$ density. There is, however, no impact of grain size on the percentage retardation for any of the three expressions indicated, only on the absolute sedimentation velocity.

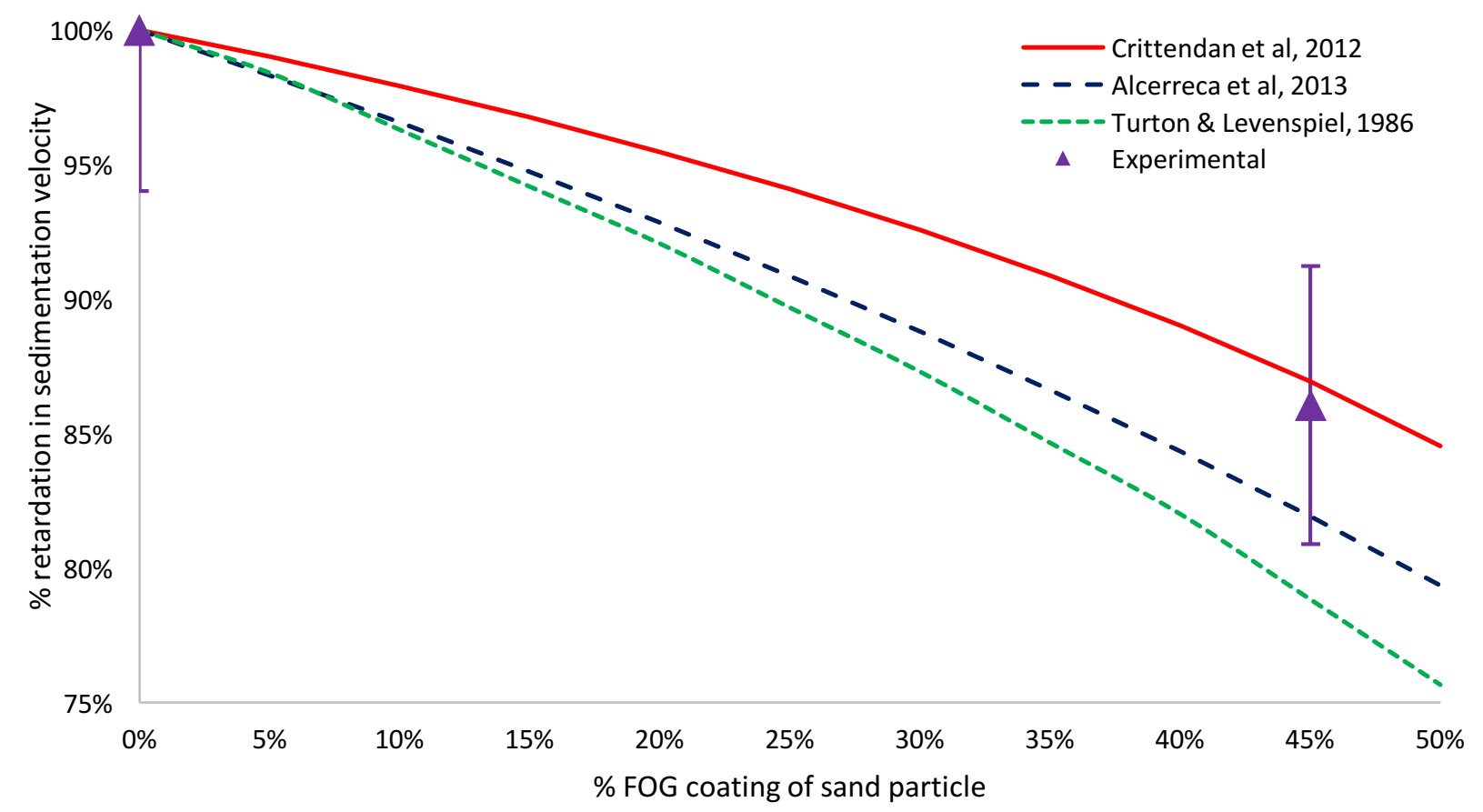

Figure 2: $\%$ retardation of settling velocity vs. $\%$ particle coating, model outputs and experimental datum

\subsubsection{Site-based accumulated grit data}

Site data indicated significant variation in the grit mean size and grit:organic matter ratio for samples extracted from five different sites (Fig. 3), primarily from AD vessels, but with $75 \%$ of the samples yielding a mean grain size in the $300-400 \mu \mathrm{m}$ range. The organic content ranged from 15 to $74 \%, 43 \%$ on average. Across all samples the standard deviation for the average data was very high ( $48 \%$ for the particle size and $61 \%$ for the organics content). Previous analysis of incoming grit to more than 15 US WwTWs revealed about $50 \%$ of the particles to be smaller in size than the standard $210 \mu \mathrm{m}$ cut-off normally specified for a degritter (Sherony and Herrick, 2015). In the case of the current the overall mean particle size was around $400 \mu \mathrm{m}$. If the organic matter can be assumed to be entirely associated with the grit then the impact on sedimentation 
would be expected to be comparable to that if the wax coating of the particle from the benchscale experiments (Section 3.1.1), for which the coating contributed $45 \%$ of the total mass.

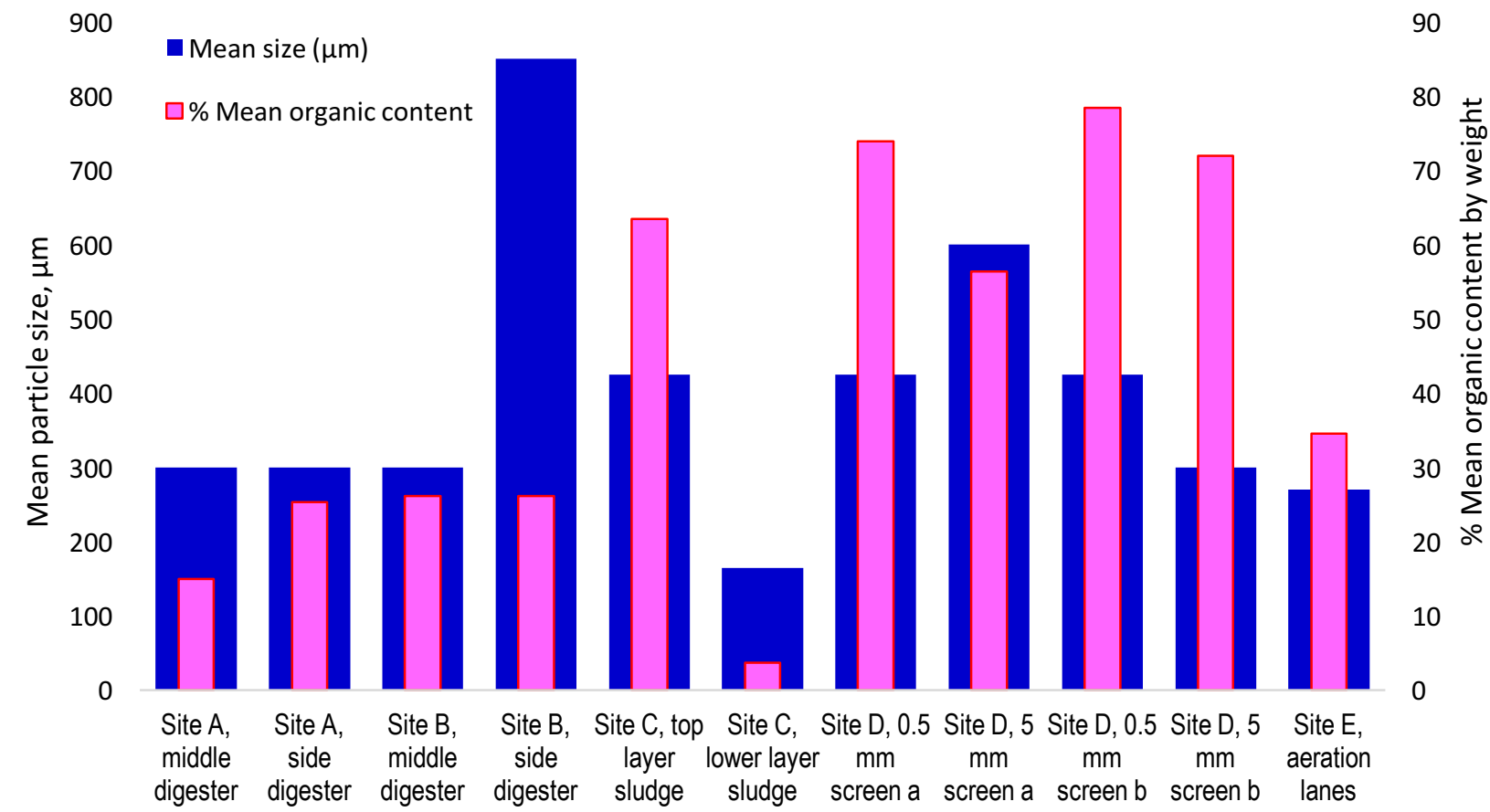

Figure 3: Particle size and \% mean organic content of grit sampled from different points across four UK WwTWs.

\subsection{Cost analysis}

Estimation of the cost of grit impacts (Table 4) was through summing the averages of each of the four cost contributions identified in Section 2.3, and then assuming that all costs could be reduced by a nominal "performance improvement factor" (PIF) through enhanced grit removal. It was assumed that the costs incurred by implementing enhanced grit removal were reduced by this factor, for example through extending periods between cleaning out of tanks or maintenance of mechanical equipment. Further assumptions comprised:

a) A mean inflation rate of $2.5 \%$ : the calculation is insensitive to this parameter for values between 0 and $5 \%$.

b) The recovered grit is subject to the same end disposal route (e.g. landfill) at the same transport and disposal cost regardless of its source (e.g. AD, aeration lane or the grit removal system itself), such that end disposal costs (generally to landfill) were ignored;

c) All possible cost contributions were included in the total cost without weighting, the weighting factor being accounted for by the frequency of operation;

d) All other possible cost contributions were ignored, including:

i. pipe blockages;

ii. the temporary closure of sludge processing facility (for remedial measures associated with clogging by grit particles) on the added cost of sites unable to export sludge;

iii. delays in refitting caused by grit blockages, where refitting of a reconditioned piece of equipment is impeded by grit and screenings accumulation;

iv. the combined effects of grit and screenings breakthrough; 
v. impaired aeration energy efficiency.

Anecdotal evidence suggests that all of the items listed in (d) have, to a greater or lesser degree, been identified by stakeholders as grit-related issues which incur a real but undefinable cost. Pipe blockages could reasonably be expected be attributable to screenings rather than grit. However, channel and pipe restriction and partial aerator occlusion can be more reasonably attributed to grit settlement in the aeration lanes (McNamara et al, 2013; Flanagan, 2014), and would be expected to increase aerator energy costs in the same way as aerator fouling.

Table 4: Grit impacts remediation costs, summary

\begin{tabular}{|c|c|c|c|c|}
\hline \multirow{2}{*}{$\begin{array}{l}\text { Flow } \\
\mathrm{m}^{3} / \mathrm{h}\end{array}$} & \multirow{2}{*}{$\begin{array}{l}\text { Freq. } \\
\mathrm{y}\end{array}$} & \multicolumn{2}{|c|}{ Cost, 2016 USD } & \multirow[t]{2}{*}{ Ref } \\
\hline & & Total & USD/ML & \\
\hline \multicolumn{5}{|c|}{ Aeration/ASP channels cleaning } \\
\hline 2843 & 1 & 65880 & 3.24 & US WwTW, 2009 \\
\hline 2843 & 1 & 82048 & 4.04 & US WwTW, 2015 \\
\hline 1583 & 5 & 122305 & 2.16 & UK WwTW, 2016 \\
\hline Average & & & 3.15 & \\
\hline \multicolumn{5}{|c|}{ Primary settlement tank refurbishment } \\
\hline 2997 & 20 & 382203 & 0.89 & US WwTW, 2009 \\
\hline \multicolumn{5}{|c|}{$A D$ digester cleaning } \\
\hline 2375 & 5 & 155000 & 2.24 & US WwTW, 2008 \\
\hline 1579 & 5 & 144300 & 3.13 & US WwTW, 2007 \\
\hline 2375 & 8 & 249000 & 2.24 & US WwTW, 2016 \\
\hline 833 & 10 & 150000 & 3.08 & UK WwTW, 2016 \\
\hline 1583 & 10 & 280000 & 3.03 & UK WwTW, 2016 \\
\hline Average & & & 2.74 & \\
\hline \multicolumn{5}{|c|}{ Wearlabrasion, pumps } \\
\hline 1893 & 1.5 & 42042 & 2.07 & US WwTW, 2009 \\
\hline 833 & 1 & 14676 & 2.47 & UK WwTW, 2016 \\
\hline Average & & & 2.27 & \\
\hline \multicolumn{5}{|c|}{ Wear/abrasion, channels } \\
\hline 1583 & 15 & 1467660 & 8.65 & UK WwTW, 2016 \\
\hline TOTAL & & & 17.71 & \\
\hline
\end{tabular}

The sum of all mean cost contributions is $\$ 17.7$ per megalitre (ML). Examination of the individual contributions indicates reasonably precise data between sources for the aeration lane and AD cleaning (both around $\$ 3$ per MLD), as well as for the mechanical equipment wear $(\$ 2.3$ per MLD). However, the single instance of abrasion of the concrete channels, leading to very costly remedial measures after an extended period of time, accounts for almost $50 \%$ of the total mean figure. If this figure, and also that for primary sedimentation tank refurbishment, are ignored then the total cost is reduced to $\$ 8.2$ per ML.

As a rough approximation, it may be assumed that grit removal is linearly related to $v_{s}$ (Butler and Davies, 2010). This being the case, a $14 \%$ reduction in $v_{s}$ produces a commensurate change in both the removal efficiency and, by implication, the cost impact. Taking the calculated cost impact of $\$ 8.2$ per ML treated the cost impact of the retardation in settling caused by formation of composite particles is around \$1.1 per ML. 
WR36544: Composite particle formation impacts on grit removal

Considering the investment cost, if a PIF of 50\% is assumed for a 25 MLD plant with an asset life of 25 years then the total cost of extraneous grit would be $\sim \$ 0.93 \mathrm{~m}$. Applying a discount rate of $4 \%$ for a mean period of 12.5 years (i.e. half the assumed asset life) reduces the cost to $\$ 0.56 \mathrm{~m}$. This figure represents the threshold investment cost difference, for a new build, between a classical degritter and an advanced technology capable of reducing the cost of the deleterious grit impacts by $50 \%$, i.e. halving grit breakthrough. The figure rises to around $\$ 3 \mathrm{~m}$ for a $90 \%$ PIF grit removal asset with an associated extraneous grit cost of $\$ 15$ per ML (Fig. 4), for the most optimistic grit removal performance improvement and the most deleterious grit impacts.

Advanced technologies such as structured or multiple-tray vortex systems can be employed to remove particles down to sizes as low as $75 \mu \mathrm{m}$, but this inevitably leads to the entrainment of increased amounts organic matter. To limit the proportion of organic matter in the grit waste stream, normally tankered off site for landfill disposal, it is normally economical to employ a grit washing and dewatering cycle to remove the organic matter from this waste stream. The grit washing cycle incurs an estimated capital and operating cost of around $50 \%$ and $50-75 \%$ of the total degritting CAPEX and OPEX respectively, the exact figure depending on the grit and wastewater characteristics. Whilst these additional costs are significant with reference to the degritter function itself, they are small compared with the amortised investment cost range indicated in Figure 4.

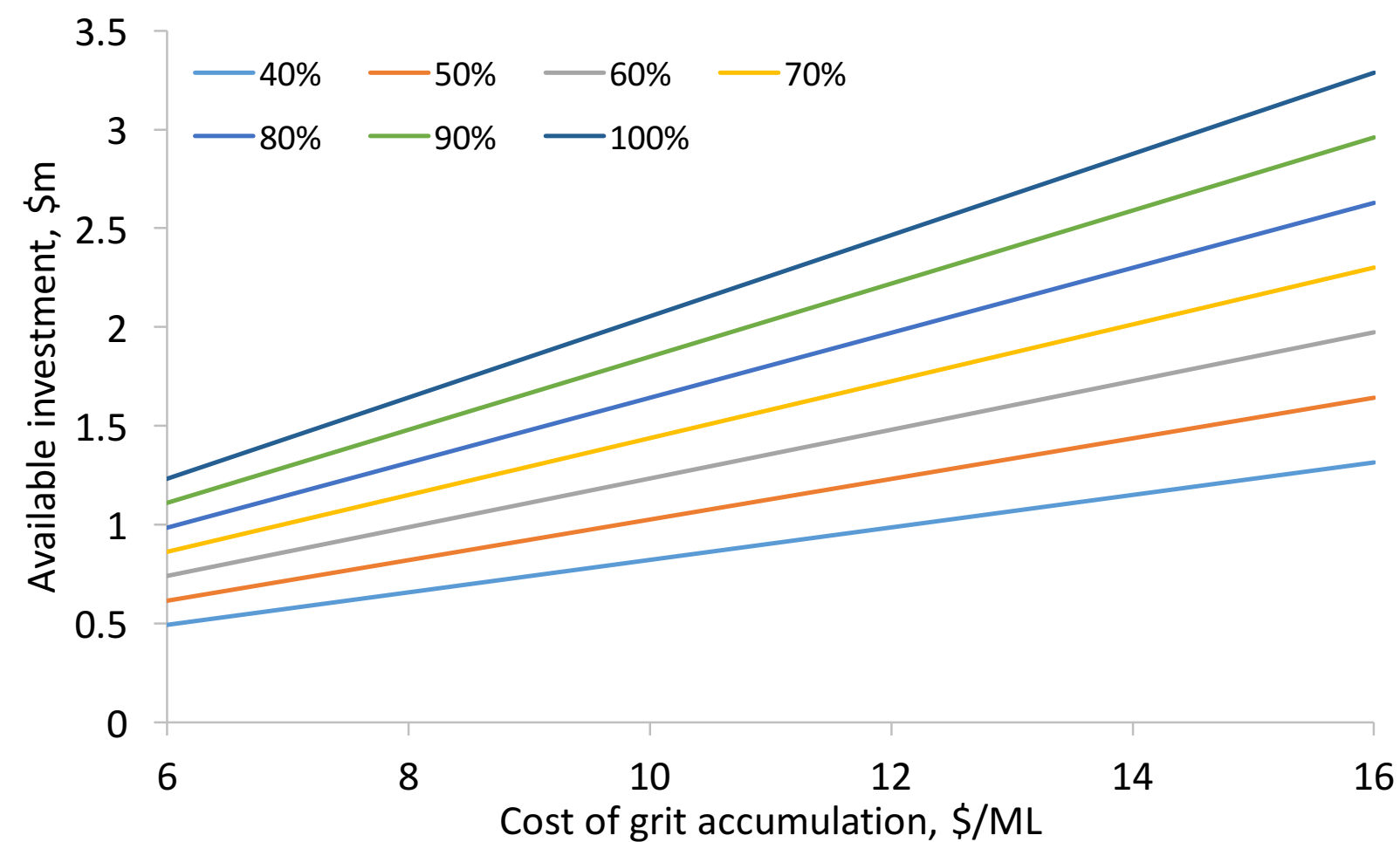

Figure 4: Available investment for grit removal vs. cost of grit accumulation for a 25 MLD plant at various \% performance improvement factors (PIF values) 


\section{$4 \quad$ Conclusions}

The impact of the association of inorganic grit particles with organic matter on the settling of the subsequent composite particle has been studied. An estimate is provided of the percentage retardation of particle settling through practical measurement of actual coated sand particles alongside model microspheres of varying sizes and densities. The size, density and settling velocity measurements were then used to identify the most appropriate mathematical models to represent settling in a quiescent liquid under transitional flow conditions. Whilst settling in a degritter actually takes place in flowing liquid, it may be assumed that the determined percentage retardation (i.e. the composite particle settling velocity normalising against that of the uncoated grit particle) would not be greatly affected by the flow regime. Moreover, computations indicated percentage retardation to be unaffected by particle size.

Outcomes of the study are as follows:

- Coating sand grains with $910 \mathrm{~kg} / \mathrm{m}^{3}$ candlewax generated composite particles which were $30 \%$ less dense, $22 \%$ larger and 14\% less settleable, on average, than the original uncoated particles.

- Sedimentation of large (1.2-1.5 mm) coated/uncoated sand particles under intermediate flow conditions more closely followed semi-empirical analytical expressions for sand grain sedimentation than the complete iterative solution for settling spheres.

- The calculated break-even capital cost of implementing an advanced degritting technology based on mitigating against $50 \%$ of reported costs incurred by remedial measures associated with grit arisings and impacts in downstream processes was $\sim \$ 0.56 \mathrm{~m}$, based on the most conservative assumptions, increasing to $\$ 3 \mathrm{~m}$ for $90 \%$ removal and a grit impact cost of $\$ 15$ per ML (megalitre, or $1000 \mathrm{~m}^{3}$ ) wastewater.

- The cost of breakthrough of $14 \%$ of the particles due to the buoyancy effect of coating of sand particles with FOG was estimated as being \$1.1 per ML.

Overall, it appears that the impact of the coating of grit with organic matter is likely to have a significant impact on their settling, and that the cost of extraneous grit in the operation and maintenance of downstream unit processes is also significant.

\section{Acknowledgment}

The assistance of Senior Lab Technician Mr Sivaprasad Valiyaveettil Narayana Menon of the Chemical Engineering Department of Qatar University is gratefully acknowledged. The cost information was provided by United Utilities and South West Water, to whom grateful thanks are given.

\section{References}

Aidun, B. (2013). Standards and Guidelines for Municipal Waterworks, Wastewater and Storm Drainage Systems part 4. Wastewater Systems Guidelines ALBERTA Government. pp. 10-132. 
Alcerreca, J. C., Silva, R., and Mendoza, E. (2013). Simple settling velocity formula for calcareous sand. Journal of Hydraulic Research, 51(2), 215-219.Butler, D., and Davies, J. (2010). Urban Drainage ( $3^{\text {rd }}$ Edition), CRC Press.

Betancourt, F., Concha, F., and Uribe, L. (2015). Settling velocities of particulate systems part 17. settling velocities of individual spherical particles in power-law non-newtonian fluids. International Journal of Mineral Processing, 143, 125-130.

British Standard (1990). Methods of test for soils for civil engineering purposes. Classification tests BS 1377, parts 2 and 3.

Butler, D., and Davies, J.W. (2010). Urban Drainage, $3^{\text {rd }}$ ed., Routledge (UK).

Cherian, C., Arnepalli, D.N., Dogga, T.S.S., Raviteja, N.B., Gorle, S.V., and Balraj, N.M (2014). Assessment of grain-size and pore-size distribution using digital image analysis. Proceedings of Indian Geotechnical Conference IGC-2014, Dec 18-20, 2014, Kakinada, India.

Concha, F., and Almendra, E. R. (1979). Settling velocities of particulate systems, 1. settling velocities of individual spherical particles. International Journal of Mineral Processing, 5(4), 349-367.

Crittenden, J.C., Trussell, R.R., Hand, D.W., Howe, K.J., and Tchobanoglous, G. (2012) Water Treatment: Principles and Design, $3^{\text {rd }}$ ed., Wiley (Hoboken, NJ).

Crittendon, J.C., Trusell, R.R., Hand, W.H., Howe, K.J., and Tchobanoglous, G. (2012). MWH's Water Treatment: Principles and Design Hardcover, $3^{\text {rd }}$ ed., John Wiley \& Sons.

Csgnetwork (2016). Specific Gravity of General Materials Table. Available from: http://www.csgnetwork.com/specificgravmattable.html (Accessed: 2 September 2016).

Cuthbertson, A. J. S., and Ervine, D. A. (2007). Experiment study of fine sand particle settling in turbulent open channel flows over rough porous beds. Journal of Hydraulic Engineering, 133(8), 905-916.

Dutta, S., Tokyay, T. E., Cataño-Lopera, Y. A., Serafino, S., \& Garcia, M. H. (2014). Application of computational fluid dynamic modelling to improve flow and grit transport in terrence J. O'brien water reclamation plant, chicago, illinois. Journal of Hydraulic Research, 52(6), 759-774.

Flanagan, E. (2014). Grit removal - identification and removal methods. Northeast Biennial WEAT Conference, May 7-8, Nacogdoches, TX.

Hafiz, S. (2013). Grit Characterisation Study Protocol-Southeast Water Pollution Control Plant (SEP). PI12-06. Sewer System Improvement Program- Program Management Consultant Contract CS-165, San Francisco, California.

Maggi, F. (2013). The settling velocity of mineral, biomineral, and biological particles and aggregates in water. Journal of Geophysical Research: Oceans. 118 (4). 2118-2132.

Mazzuoli, M., Seminara, G., and Vittori, G. (2014). Settling of heavy particles in a turbulent stokes layer: Numerical simulations. Advances in Water Resources, 72, 2-14.

McNair, J. N., and Newbold, J. D. (2012). Turbulent particle transport in streams: Can exponential settling be reconciled with fluid mechanics? Journal of Theoretical Biology, 300, 6280 . 
McNamara, B., Layne, J., Hyre, M., Kinnear, D. and Bott, C. (2012). Evaluation of Three Fullscale Grit Removal Processes using CFD Modeling. Conf. Proc. WEFTEC 2012 (29/10-3/9, New Orleans) 9 6008-6030.

McNamara, B., Sherony, M., and Herrick, P. (2013). Relative performance of grit removal systems. Journal of New England Water Environment Association, 47(3), 42-48

McNamara, B., Sherony, M., and Herrick, P. (2014). Relative performance of grit removal systems. The Conduit, Spring 2014 ed., 48-55.

Moaveni, S. (2011). Engineering Fundamentals: An Introduction to Engineering, SI ed., Cengage Learning (Stamford, US)

Morales, L., \& Reinhart, D. (1984). Full-scale evaluation of aerated grit chambers. Journal of the Water Pollution Control Federation, 56(4), 337-343.

Munoz, A., \& Young, S. (2009). Two-dimensional model for predicting performance of aerated grit chambers. Canadian Journal of Civil Engineering, 36(9), 1567-1578.

Osei, K., Gwinn, A., and Andoh, R. Y. G. (2012). Development of a column to measure settling velocity of grit. Paper presented at the World Environmental and Water Resources Congress 2012: Crossing Boundaries, Proceedings of the 2012 Congress, 1327-1333.

Patel, T., Gill, L., and Faram, M. G. (2011). Grit removal from wastewater using secondary currents in open-channel flow around bends. Journal of Environmental Engineering, 137(11), 1026-1039.

Shahi, S., and Kuru, E. (2015). An experimental investigation of settling velocity of natural sands in water using particle image shadowgraph. Powder Technology, 281, 184-192.

Sherony, M. (2014). True grit: effective removal through management. Filtration and Separation. 51 (2) 38-40.

Sherony, M., and Herrick, P. (2015). Florida Water Resources Journal, Jan edn, 48-53.

Simetric (2016). Mass, Weight, Density or Specific Gravity of Bulk Materials. Available from: http://www.simetric.co.uk/si_materials.htm (Accessed: 2 September 2016).

Sperling, M. (2007). Wastewater characteristics, treatment and disposal. IWA Publishing, London.

Terfous, A., Hazzab, A., and Ghenaim, A. (2013). Predicting the drag coefficient and settling velocity of spherical particles. Powder Technology, 239, 12-20.

Turton, and Levenspiel (1986). A short note on the drag correlation for spheres. Powder Technology, 47 (1936) 83-86.

Tyack, J.N., Hedges P. and Smisson R. P. M. (1996). The relationship between settling velocity grading and the characteristics of the contributing catchment. Wat. Sci. Tech., 33 (9) 135-142.

USEPA. (2003) Wastewater Technology Fact Sheet, Screening and Grit Removal.

Yan, P., Ji, F., Fan, J., and Zong, S. (2014). Grit separation module performance and influencing factors for grit removal efficiency from activated sludge. Separation Science and Technology (Philadelphia), 49(1), 121-129. 
WR36544: Composite particle formation impacts on grit removal

Yang, H., Fan, M., Liu, A., and Dong, L. (2015). General formulas for drag coefficient and settling velocity of sphere based on theoretical law. International Journal of Mining Science and Technology, 25(2), 219-223.

Yesiller, N., Hanson, J., Cox, J. and Noce, D. (2014). Determination of specific gravity of municipal solid waste. Waste Management. 34(5) 848-858. 